\title{
Predictors of early continence following robot-assisted radical prostatectomy
}

\author{
Hugo Lavigueur-Blouin, MD, ${ }^{*}$ Alina Camacho Noriega, MD; ${ }^{*}$ Roger Valdivieso, MD, ${ }^{*}$ Pierre-Alain Hueber, MD; \\ Marc Bienz, MD; Naif Alhathal, MD; ${ }^{*}$ Mathieu Latour, MD; ${ }^{*}$ Quoc-Dien Trinh, MD, FRCSC; ${ }^{+}$ \\ Assaad El-Hakim, MD, FRCSC;, Kevin C. Zorn, MD, FRCSC*
}

*Cancer Prognostics and Health Outcomes Unit, Centre Hospitalier de I'Université de Montréal, Montreal, QC; 'Division of Urologic Surgery and Center for Surgery and Public Health, Brigham and Women's Hospital, Harvard Medical School, Boston, MA; \$Hôpital du Sacré-Cœur de Montréal, Université de Montréal, Montreal, QC

Cite as: Can Urol Assoc J 2015(1-2):e93-7. http://dx.doi.org/10.5489/cuaj.2086

Published online February 9, 2015.

\section{Abstract}

Introduction: Functional outcomes after robot-assisted radical prostatectomy (RARP) greatly influence patient quality of life. Data regarding predictors of early continence, especially 1 month following RARP, are limited. Previous reports mainly address immediate or 3-month postoperative continence rates. We examine preoperative predictors of pad-free continence recovery at the first follow-up visit 1 month after RARP.

Methods: Between January 2007 and January 2013, preoperative and follow-up data were prospectively collected for 327 RARP patients operated on by 2 fellowship-trained surgeons (AEH and KCZ). Patient and operative characteristics included age, body mass index (BMI), staging, preoperative prostate-specific antigen (PSA), prostate weight, International Prostate Symptom Score (IPSS), Sexual Health Inventory for Men (SHIM) score and type of nervesparing performed. Continence was defined by 0 -pad usage at 1 month follow-up. Univariate and multivariate logistic regression models were used to assess for predictors of early continence.

Results: Overall, 44\% of patients were pad-free 1 month postRARP. In multivariate regression analysis, age (odds ratio [OR] 0.946, confidence interval [CI] 95\%: 0.91, 0.98) and IPSS (OR: 0.953, Cl 95\%: 0.92, 0.99) were independent predictors of urinary continence 1 month following RARP. Other variables (BMI, staging, preoperative PSA, SHIM score, prostate weight and type of nerve-sparing) were not statistically significant predictors of early continence. Limitations of this study include missing data for comorbidities, patient use of pelvic floor exercises and patient maximal activity. Moreover, patient-reported continence using a 0 -pad usage definition represents a semiquantitative and subjective measurement.

Conclusion: In a broad population of patients who underwent RARP at our institution, $44 \%$ of patients were pad-free at 1 month. Age and IPSS were independent predictors of early continence after surgery. Men of advanced age and those with significant lower urinary tract symptoms prior to RARP should be counselled on the increased risk of urinary incontinence in the early stages.

\section{Introduction}

Urinary continence following robot-assisted radical prostatectomy (RARP) is one of the main concerns for patients who undergo this procedure. It has been suggested that urinary continence has a higher impact on quality of life than sexual functioning. ${ }^{1}$ In the preoperative setting, data concerning this outcome can help with patient counselling by offering a more accurate and individualized prediction of expected results.

There is currently a lack of data regarding predictors of early continence 1 month following RARP for localized prostate cancer. The early postoperative period can be stressful and tiring for patients; we therefore sought to examine factors that can influence early continence recovery to improve preoperative counselling. Currently, studies mainly address the potential predictors of continence at 3,6 and 12 months post RARP. Specifically, Jeong and colleagues observed that age, prostatic apex shape and membranous urethral length are factors that are associated with continence recovery within 1 year. $^{2}$ In a recent study, Galfano and colleagues found that a surgical technique sparing the Reitzus structures yielded higher early continence rates. ${ }^{3}$ It has also been implied that younger age, positive surgical margins and absence of preoperative urinary incontinence are clear predictors of better functional outcomes. ${ }^{4}$ Finally, Sammon and colleagues concluded that the type of nerve-sparing performed and placement of a percutaneous suprapubic tube for bladder drainage postoperatively were independently predictive of never requiring a pad after RARP. ${ }^{5}$ According to a recently published consensus panel on post-RARP incontinence, the following were risk factors for UI after RARP: increased age, obesity, short membranous urethral length on both preoperative and postoperative endorectal magnetic resonance imaging, post-prostatectomy anastomotic strictures, low institutional and/or surgeon caseload, non-nerve sparing procedures, non-bladder neck preservation, and high prostate volume. ${ }^{6}$ 
In this study, we conducted a multi-surgeon study to assess predictors of continence recovery after RARP at the 1-month follow-up.

\section{Methods}

\section{Data source}

After receiving institutional review board approval, we used a database of 604 RARP procedures performed at our institution from January 2007 to January 2013. Demographic information, medical parameters, surgical details and functional outcomes were prospectively collected. Of the 604 patients, 277 had incomplete data; the remaining 327 patients were included in this study cohort. During the period in which data was collected, we gathered data from cases performed by 4 surgeons. Pathologic and intraoperative characteristics were recorded for all patients, but surgeons other than $\mathrm{KCZ}$ and $\mathrm{AEH}$ did not record pad-usage systematically on followup, therefore we only included data from patients operated on by KCZ and $\mathrm{AEH}$.

\section{Surgical technique}

Both surgeons ( $\mathrm{KCZ}$ and $\mathrm{AEH}$ ) had overcome the learning curve, each with more than 200 robotic cases prior to the study. The surgical technique was performed as previously reported. ${ }^{7-10}$ Both surgeons used the barbed polyglyconate suture (V-Loc-suture, Covidien Inc.) for vesico-urethral anastomosis, ${ }^{11}$ which included posterior rhabdo-sphincter reconstruction. ${ }^{12}$

\section{Outcome measures and definitions}

All patients completed International Prostate Symptom Score (IPSS) and Sexual Health Inventory for Men (SHIM) questionnaires preoperatively and at each follow-up visit. The recorded demographic and preoperative characteristics included as covariates in the analyses were age, body mass index (BMI), preoperative prostate-specific antigen (PSA), prostate size, IPSS, SHIM, type of nerve-sparing performed and pathologic stage. Both the SHIM and the IPSS were grouped by severity of the erectile dysfunction and lower urinary tracts symptoms, respectively. A strict definition of continence was used; continence was defined as a 0-pad scenario. Cases in which the patient used a security pad were sorted in the incontinent group. The first follow-up visit was at 1 month for the entire cohort.

\section{Statistical analyses}

Categorical distributions were reported as counts (\%) and continuous variables as medians and interquartile range. The Chi-square test was used to assess differences in distributions among categorical variables. The Mann-Whitney $U$ test was used to assess the difference in distributions among continuous variables.

Univariable and multivariable logistic regression models were constructed to assess for predictors of continence 1 month following surgery. All tests were two-sided, with a statistical significance set at $p<0.05$. Statistical analyses were performed with the software package SPSS (IBM Corporation, version 21, Armonk, NY).

\section{Results}

Overall, 44\% of patients (144/327) achieved 0-pad continence 1 month after RARP (Table 1). When using a 0-1 security pad definition for achievement of continence, $63 \%$ of patients (205/327) could be considered continent. Patients with return of continence requiring 0-pad usage tended to be younger and tended to have a lower preoperative IPSS (Table 1).

On univariable analysis, patient and operative characteristics associated with continence 1 month following RARP were younger age (odds ratio [OR] 0.936, 95\% confidence interval $[\mathrm{Cl}]$ 0.90, 0.97), smaller prostate size (OR 0.983, $95 \% \mathrm{Cl} 0.97,1)$ and a moderate IPSS, low IPSS as referent (OR 0.521, 95\% Cl 0.32, 0.85) (Table 2).

On multivariable regression analysis, age $(\mathrm{OR} 0.95, \mathrm{Cl}$ $95 \% 0.91,0.98$ ) and moderate IPSS (OR 0.549, CI 95\% $0.32,0.93)$ were independent predictors of continence 1 month following RARP (Table 3). Other variables such as $\mathrm{BMI}$, preoperative PSA, prostate weight, SHIM score, type of nerve-sparing and pathological staging were not statistically significant predictors of early continence.

\section{Discussion}

While many studies have evaluated predictors of urinary continence at 3, 6 and 12 months, few have examined the characteristics associated with return of continence 1 month after RARP. Many definitions have been employed, including pad-free status, leak-free status and urinary function composite scores. As expected, studies using a more narrow definition achieved more conservative results. ${ }^{13}$ In this analysis, we examined patient, operative and pathologic characteristics associated with continence defined by a strict pad-free criterion. To our knowledge, this is the first study to evaluate predictors of continence 1 month following radical prostatectomy in a cohort consisting only of RARP procedures. All 327 procedures were performed by fellowship- 


\begin{tabular}{|c|c|c|c|c|}
\hline & Total $(n=327)$ & $\begin{array}{l}\text { Continent at } 1 \text { month } \\
\qquad(n=144)\end{array}$ & $\begin{array}{l}\text { Incontinent at } 1 \text { month } \\
\qquad(\mathrm{n}=183)\end{array}$ & $p$ value \\
\hline Age, median (IQR) & $60(55-65)$ & $59(54-63)$ & $62(57-66)$ & 0.001 \\
\hline$\leq 55$ & 88 & $50(57 \%)$ & $38(43 \%)$ & 0.002 \\
\hline $56-65$ & 166 & $70(42 \%)$ & $96(58 \%)$ & \\
\hline$\geq 66$ & 73 & $24(33 \%)$ & $49(67 \%)$ & \\
\hline BMI, median (IQR) & $27(25-30)$ & $27(24-29)$ & $27(25-30)$ & 0.118 \\
\hline Preoperative PSA, median (IQR) & $5.3(4.2-7.4)$ & $5.0(4.1-7.1)$ & $5.6(4.2-7.6)$ & 0.164 \\
\hline Prostate weight, median (IOR) & $45(37-57)$ & $44(36-54)$ & $47(38-60)$ & 0.055 \\
\hline Preoperative IPSS & & & & 0.025 \\
\hline Mild (0-7) & 198 & $99(50 \%)$ & $99(50 \%)$ & \\
\hline Moderate (8-19) & 108 & $37(34 \%)$ & $71(66 \%)$ & \\
\hline Severe (20-35) & 21 & $8(38 \%)$ & $13(62 \%)$ & \\
\hline Preoperative SHIM & & & & 0.107 \\
\hline No ED (22-25) & 162 & $80(49 \%)$ & $82(51 \%)$ & \\
\hline Mild (17-21) & 82 & $32(34 \%)$ & $50(61 \%)$ & \\
\hline Mild to moderate (12-16) & 36 & $18(50 \%)$ & $18(50 \%)$ & \\
\hline Moderate (8-11) & 10 & $2(20 \%)$ & $8(80 \%)$ & \\
\hline Severe (1-7) & 37 & $12(32 \%)$ & $25(68 \%)$ & \\
\hline Nerve-sparing & & & & 0.089 \\
\hline None & 74 & $28(38 \%)$ & $46(62 \%)$ & \\
\hline Unilateral & 52 & $18(35 \%)$ & $34(65 \%)$ & \\
\hline Bilateral & 201 & $98(49 \%)$ & $103(51 \%)$ & \\
\hline pStage & & & & 0.632 \\
\hline $\mathrm{T} 2$ & 236 & $102(43 \%)$ & $134(57 \%)$ & \\
\hline T3 & 91 & $42(46 \%)$ & $49(54 \%)$ & \\
\hline
\end{tabular}

RARP: robot-assisted radical prostatectomy; IQR: interquartile range; IPSS: International prostate symptom score; PSA: prostate-specific antigen; SHIM: sexual health inventory for men; ED: erectile dysfunction.

trained surgeons (KCZ and $\mathrm{AEH}$ ) who had exceeded the learning curve for RARP.

In our group, $44 \%$ of patients were pad-free 1 month following RARP. Various continence rates are reported 1 month following RARP depending on the definition used. When using a strict 0-pad definition, authors have reported 1 month continence rates varying between 26 and $72 \%,{ }^{14-17}$ while other studies reported rates varying between $65 \%$ and $85 \%$ for a 0-1 safety pad definition. ${ }^{18-20}$ Comparatively, in our cohort, the continence rate 1 month after RARP was $44 \%$ using a strict 0-pad definition, and 63\% using a 0-1 safety pad definition.

Multiple studies have previously demonstrated that age is one of the main predictors of return of continence at 6 weeks, 3 months and 12 months following RARP. ${ }^{21-24}$ In a study assessing time to continence following RARP, Mendiola and colleagues have demonstrated that younger men will likely have an earlier return of continence compared to older men. However, continence outcomes were equal among age groups after 1 year of follow-up..$^{25}$ To our knowledge, this is the first study to report age as an independent predictor of urinary continence at 1 month in a cohort consisting purely of robot-assisted procedures. This finding can be useful for patient counselling prior to surgery to better manage early postoperative expectations; physicians can affirm with greater confidence that men 55 years old and younger are more likely to be completely pad-free 1 month after surgery. In our study, $57 \%$ of men in this age group did not need pads 1 month following RARP. Conversely, men over 65 can be advised that continence is less likely; our data indicated that only $33 \%$ are pad-free 1 month after surgery.

We also demonstrated that a moderate IPSS is an independent predictor of pad usage 1 month following RARP. This finding has been reported by Shikanov and colleagues; they showed a higher likelihood of continence at 1 year with a lower baseline IPSS. These authors have hypothesized that higher preoperative IPSS likely represents detrusor overactivity due to benign prostatic hyperplasia (BPH), which may contribute significantly to incontinence after surgery. ${ }^{23}$ Our study did not demonstrate high IPSS as independently associated with this outcome. This could be due to a relatively low number of patients who had a high preoperative score in our cohort.

It has been demonstrated that prostate volume is an independent predictor of recovery of urinary function after radi- 


\begin{tabular}{|c|c|c|}
\hline & $\begin{array}{l}\text { Univariable OR } \\
\quad(95 \% \mathrm{Cl})\end{array}$ & $p$ value \\
\hline Age (continuous) & $0.936(0.90,0.97)$ & $<0.001$ \\
\hline BMI (continuous) & $0.957(0.91,1.01)$ & 0.111 \\
\hline Preoperative PSA (continuous) & $1.002(0.96,1.04)$ & 0.911 \\
\hline Prostate weight (continuous) & $0.983(0.97,1)$ & 0.017 \\
\hline \multicolumn{3}{|l|}{$\begin{array}{l}\text { Preoperative IPSS (Mild [0-7] as } \\
\text { referent) }\end{array}$} \\
\hline Moderate (8-19) & $0.521(0.32,0.85)$ & 0.008 \\
\hline Severe (20-35) & $0.615(0.24,1.55)$ & 0.303 \\
\hline \multicolumn{3}{|c|}{$\begin{array}{l}\text { Preoperative SHIM (No ED [22-25] as } \\
\text { referent) }\end{array}$} \\
\hline Mild (17-21) & $0.656(0.38,1.13)$ & 0.126 \\
\hline Mild to moderate (12-16) & $1.025(0.5,2.11)$ & 0.947 \\
\hline Moderate (8-11) & $0.256(0.05,1.24)$ & 0.091 \\
\hline Severe (1-7) & $0.492(0.23,1.05)$ & 0.065 \\
\hline \multicolumn{3}{|l|}{ Nerve-sparing (None as referent) } \\
\hline Unilateral & $0.870(0.42,1.82)$ & 0.712 \\
\hline Bilateral & $1.563(0.91,2.7)$ & 0.108 \\
\hline pStage $\geq p T 3 a(p T 2$ as referent) & $1.126(0.69,1.83)$ & 0.632 \\
\hline
\end{tabular}

cal prostatectomy. ${ }^{26,27}$ In a study by Jeong and colleagues, prostate volume was independently associated with continence at 12 months in a cohort consisting equally of RARP and RRP operated patients, although it was a predictor of 0 -pad usage at 1 and 3 months following prostatectomy. ${ }^{27}$ It has been suggested that wider dissection of the bladder neck for large prostates can contribute to this association. ${ }^{28}$ While smaller prostate volume was associated with continence at 1 month on univariate analysis, this characteristic was not an independent predictor of continence on multivariate analysis.

It has been reported that SHIM score is a predictor of continence recovery at 3, 6 and 12 months. ${ }^{22,23,29}$ Our analyses did not show a statistically significant association at 1 month. It has also previously been suggested that degree of nerve sparing is associated with improved postprostatectomy functional urinary outcomes immediately after catheter removal, as well as over the first postoperative year. ${ }^{5,30}$ In our study, nerve sparing was not associated with improved continence following RARP. Some studies have suggested that BMI, staging and preoperative PSA were predictors of continence at 3 and 12 months; however, our analyses did not demonstrate these variables as predictors of early continence.

There are several limitations of our study. First, this was a retrospectively analyzed study with a small overall group. Our study was done at a single centre and no baseline urodynamic study was done to verify the presence of detru-

\begin{tabular}{|c|c|c|}
\hline & $\begin{array}{l}\text { Multivariable OR } \\
\text { (95\% Cl) }\end{array}$ & p value \\
\hline Age (continuous) & $0.95(0.91,0.98)$ & 0.012 \\
\hline BMI (continuous) & $0.965(0.91,1.02)$ & 0.229 \\
\hline Preoperative PSA (continuous) & $1.019(0.98,1.06)$ & 0.377 \\
\hline Prostate weight (continuous) & $0.996(0.98,1.01)$ & 0.620 \\
\hline \multicolumn{3}{|l|}{$\begin{array}{l}\text { Preoperative IPSS (Mild [0-7] as } \\
\text { referent) }\end{array}$} \\
\hline Moderate (8-19) & $0.549(0.32,0.93)$ & 0.027 \\
\hline Severe (20-35) & $0.745(0.26,2.12)$ & 0.581 \\
\hline \multicolumn{3}{|c|}{$\begin{array}{l}\text { Preoperative SHIM (No ED [22-25] as } \\
\text { referent) }\end{array}$} \\
\hline Mild (17-21) & $0.888(0.49,1.62)$ & 0.698 \\
\hline Mild to moderate (12-16) & $1.468(0.66,3.29)$ & 0.35 \\
\hline Moderate (8-11) & $0.285(0.06,1.45)$ & 0.131 \\
\hline Severe (1-7) & $0.816(0.36,1.87)$ & 0.631 \\
\hline \multicolumn{3}{|l|}{ Nerve-sparing (None as referent) } \\
\hline Unilateral & $0.655(0.3,1.44)$ & 0.291 \\
\hline Bilateral & $1.114(0.59,2.1)$ & 0.738 \\
\hline pStage $\geq \mathrm{pT} 3 a$ (pT2 as referent) & $1.093(0.64,1.87)$ & 0.744 \\
\hline
\end{tabular}

sor hyperactivity preoperatively. We did not collect data on the consistency of preoperative pelvic floor exercises and training - which plays a significant role in postoperative continence. Particularly for 1 month outcomes, patient maximal physical activity was not collected. This would have played a significant role in stress urinary incontinence events if one were to be more sedentary and not performing usual activities. We did not assess comorbidities or study specifically for neurological conditions and diabetes. Finally, patient-reported achievement of continence by a zero-pad usage definition was a semiquantitative measurement with a subjective aspect.

It is clear that other predictive factors with stronger predictive ability are needed, beyond the traditional factors discussed above. We recently published a report on a novel uroflow Stop Test at the time of catheter removal post-RARP. Our results yielded a very powerful discrimination ability at 1,3 and 6 months postoperatively with pad-free continence rates in positive versus negative Stop Test groups of $62 \%$ versus $7 \%(p<0.001), 85 \%$ versus $28 \%(p<0.001)$, and $93 \%$ versus $67 \%(p=0.001)$, respectively. ${ }^{31}$

\section{Conclusion}

In a broad population of patients who underwent RARP at our institution, $44 \%$ of patients were pad-free at 1 month. Age and IPSS were independent predictors of early conti- 
nence after surgery. Men of advanced age and those with significant lower urinary tract symptoms prior to RARP should be counselled appropriately on the increased risk of urinary incontinence in the early stages after surgery.

Competing interests: Dr. Lavigueur-Blouin, Dr. Camacho Noriega, Dr. Valdivieso, Dr. Hueber, Dr. Bienz, Dr. Alhathal, Dr. Latour and Dr. El-Hakim all declare no competing financial or personal interests. Dr. Zorn is an advisor, speaker, and proctor for Greenlight laser surgery from AMS. Dr. Trinh received honorarium from Intuitive Surgical in the past.

This paper has been peer-reviewed.

\section{References}

1. Schroeck FR, Krupski TL, Sun L, et al. Satisfaction and regret after open retropubic or robot-assisted laparoscopic radical prostatectomy. Eur Urol 2008;54:785-93. http://dx.doi.org/10.1016/i.eururo.2008.06.063

2. Jeong SJ, Kim HJ, Kim JH, et al. Urinary continence after radical prostatectomy: Predictive factors of recovery after 1 year of surgery. Int J Urol 2012;19:1091-8. http://dx.doi.org/10.1111/j.14422042.2012.03106.x

3. Galfano A, Di Trapani D, Sozzi F, et al. Beyond the learning curve of the Retzius-sparing approach for robotassisted laparoscopic radical prostatectomy: Oncologic and functional results of the first 200 patients with >/=1 year of follow-up. Eur Urol 2013;64:974-80. http://dx.doi.org/10.1016/i.eururo.2013.06.046

4. Geraerts I, Van Poppel H, Devoogdt N, et al. Prospective evaluation of urinary incontinence, voiding symptoms and quality of life after open and robot-assisted radical prostatectomy. BJU Int 2013;112:936-43.

5. Sammon JD, Sharma $P$, Trinh Q-D, et al. Predictors of immediate continence following robot-assisted radical prostatectomy. J Endourol 2013;27:442-6. http://dx.doi.org/10.1089/end.2012.0312

6. Montorsi F, Wilsonb TG, Rosen RC, et al. Best practices in robot-assisted radical prostatectomy: Recommendations of the Pasadena Consensus Panel. Eur Urol 2012;62:368-81. http://dx.doi. org/10.1016/i.eururo.2012.05.057

7. Al-Hathal N, El-Hakim A. Perioperative, oncological and functional outcomes of the first robotic prostatectomy program in Quebec: Single fellowship-trained surgeon's experience of 250 cases. Can Urol Assoc J 2013;7:326-32. http://dx.doi.org/10.5489/cuai.319

8. Menon M, Tewari A, Peabody J, et al. Vattikuti Institute prostatectomy: Technique. J Urol 2003; 169:228992. http://dx.doi.org/10.1097/01.ju.0000067464.53313.dd

9. Valdivieso RF, Hueber PA, Zorn KC. Robot assisted radical prostatectomy: How I do it. Part I: Patient preparation and positioning. Can J Urol 2013;20:6957-61.

10. Valdivieso RF, Hueber PA, Zorn KC. Robot assisted radical prostatectomy: How I do it. Part II: Surgical technique. Can J Urol 2013;20:7073-8.

11. Zorn KC, Trinh Q-D, Jeldres C, et al. Prospective randomized trial of barbed polyglyconate suture to facilitate vesico-urethral anastomosis during robot-assisted radical prostatectomy: Time reduction and cost benefit. BJU Int 2012;109:1526-32. http://dx.doi.org/10.1111/i.1464-410X.2011.10763.x

12. Gautam G, Rocco B, Patel VR, et al. Posterior rhabdosphincter reconstruction during robot-assisted radical prostatectomy: Critical analysis of techniques and outcomes. Urology 2010;76:734-41. http://dx.doi. org/10.1016/i.urology.2010.01.073

13. Reynolds WS, Shikanov SA, Katz MH, et al. Analysis of continence rates following robot-assisted radical prostatectomy: Strict leak-free and pad-free continence. Urology 2010;75:431-6. http://dx.doi. org/10.1016/j.urology.2009.07.1294

14. Kim IY, Hwang EA, Mmeje C, et al. Impact of posterior urethral plate repair on continence following robot-assisted laparoscopic radical prostatectomy. Yonsei Med J 2010;51:427-31. http://dx.doi. org/10.3349/ymi.2010.51.3.427
15. Coelho RF, Chauhan S, Orvieto MA, et al. Influence of modified posterior reconstruction of the rhabdosphincter on early recovery of continence and anastomotic leakage rates after robot-assisted radical prostatectomy. Eur Urol 2011;59:72-80. http://dx.doi.org/10.1016/i.eururo.2010.08.025

16. Sammon JD, Muhletaler F, Peabody J0, et al. Long-term functional urinary outcomes comparing single-vs double-layer urethrovesical anastomosis: Two-year follow-up of a two-group parallel randomized controlled trial. Urology 2010;76:1102-7. http://dx.doi.org/10.1016/j.urology.2010.05.052

17. Hurtes $X$, Rouprêt $M$, Vaessen $C$, et al. Anterior suspension combined with posterior reconstruction during robot-assisted laparoscopic prostatectomy improves early return of urinary continence: A prospective randomized multicentre trial. BJU Int 2012;1 10:875-83. http://dx.doi.org/10.1111/i.1464410X.2011.10849.X

18. Menon M, Muhletaler F, Campos $M$, et al. Assessment of early continence after reconstruction of the periprostatic tissues in patients undergoing computer assisted (robotic) prostatectomy: Results of a 2 group parallel randomized controlled trial. J Urol 2008;180:1018-23. http://dx.doi.org/10.1016/i. juro.2008.05.046

19. Krane $L S$, Wambi C, Bhandari A, et al. Posterior support for urethrovesical anastomosis in robotic radical prostatectomy: Single surgeon analysis. Can I Urol 2009;16:4836-40.

20. Koliakos N, Mottrie A, Buffi N, et al. Posterior and anterior fixation of the urethra during robotic prostatectomy improves early continence rates. Scand J Urol Nephrol 2010;44:5-10. http://dx.doi. org/10.3109/00365590903413627

21. Novara G, Ficarraemail V, D'elia $C$, et al. Evaluating urinary continence and preoperative predictors of urinary continence after robot assisted laparoscopic radical prostatectomy. J Urol 2010;184:1028-33. http://dx.doi.org/10.1016/i.juro.2010.04.069

22. Kim JJ, Ha Y-S, Kim JH, et al. Independent predictors of recovery of continence 3 months after robotassisted laparoscopic radical prostatectomy. J Endourol 2012;26:1290-5. http://dx.doi.org/10.1089/ end.2012.0117

23. Shikanov S, Desai V, Razmaria A, et al. Robotic radical prostatectomy for elderly patients: Probability of achieving continence and potency 1 year after surgery. J Urol 2010;183:1803-7. http://dx.doi. org/10.1016/i.juro.2010.01.016

24. Lee DJ, Cheetham P, Badani KK. Predictors of early urinary continence after robotic prostatectomy. Can J Urol 2010;17:5200-5.

25. Mendiola FP, Zorn KC, Mikhail AA, et al. Urinary and sexual function outcomes among different age groups after robot-assisted laparoscopic prostatectomy. J Endourol 2008;22:519-24. http://dx.doi. org/10.1089/end.2006.9845

26. Konety BR, Sadetsky N, Carroll PR, et al. Recovery of urinary continence following radical prostatectomy: The impact of prostate volume-analysis of data from the CaPSURE Database. J Urol 2007;177:1423-5; discussion 1425-6. http://dx.doi.org/10.1016/i.juro.2006.11.089

27. Jeong SJ, Yeon JS, Lee JK, et al. Development and validation of nomograms to predict the recovery of urinary continence after radical prostatectomy: Comparisons between immediate, early, and late continence. World J Urol 2014;32:437-44. http://dx.doi.org/10.1007/s00345-013-1127-y. Epub 2013 Jul 6.

28. Boczko J, Erturk E, Golijanin D, et al. Impact of prostate size in robot-assisted radical prostatectomy. J Endourol 2007;21:184-8. http://dx.doi.org/10.1089/end.2006.0163

29. Takenaka A, Soga H, Kurahashi T, et al. Early recovery of urinary continence after laparoscopic versus retropubic radical prostatectomy: Evaluation of preoperative erectile function and nerve-sparing procedure as predictors. Int Urol Nephrol 2009;41:587-93. http://dx.doi.org/10.1007/s11255-008-9480-2

30. Kaye DR, Hyndman ME, L. Segal RL, et al. Urinary outcomes are significantly affected by nerve sparing quality during radical prostatectomy. Urology 2013;82:1348-53. http://dx.doi.org/10.1016/i. urology.2013.06.067

31. El-Hakim A, A-Hathal N, Al-Qaoud T, et al. Novel uroflow stop test at time of catheter removal is a strong predictor of early urinary continence recovery following robotic-assisted radical prostatectomy: A pilot study. Neurourol Urodyn 2013. http://dx.doi.org/10.1002/nau.22481. Epub 201327 Aug.

Correspondence: Dr. Kevin Zorn, University of Montréal Hospital Centre, 235 Boul. Rene Levesque East, Suite 301, Montréal, QC H2X 1N8; kevin.zon@gmail.com 